\title{
Separation of ursodeoxycholic acid by silylation crystallization
}

\author{
Xiaolei Ma and Xuejun Cao ${ }^{*}$
}

\begin{abstract}
Background: Ursodeoxycholic acid is an important clinical drug in the treatment of liver disease. In our previous work, ursodeoxycholic acid was prepared by electroreduction of 7-ketolithocholic acid. The separation of ursodeoxycholic acid from the electroreduction product $(47 \%(\mathrm{~W} / \mathrm{W})$ ursodeoxycholic acid) by silylation crystallization is described herein.

Results: $\mathrm{N}, \mathrm{N}$-dimethylformamide was used as the solvent, whereas hexamethyldisilazane was the reaction agent. The optimal material ratio of electroreduction product/ $\mathrm{N}, \mathrm{N}$-dimethylformamide/hexamethyldisilazane was found to be 1:10:2 ( $\mathrm{W} / \mathrm{V} / \mathrm{V})$. The reaction proceeded for $2 \mathrm{~h}$ at $60^{\circ} \mathrm{C}$, and the corresponding silylation derivative was separated by crystallization and pure ursodeoxycholic acid was recovered by $5 \%$ acid hydrolysis at $50^{\circ} \mathrm{C}$ for $0.5 \mathrm{~h}$. The maximum recovery and purity of ursodeoxycholic acid were $99.8 \%$ and $99.5 \%$, respectively.
\end{abstract}

Conclusion: Ursodeoxycholic acid with high purity and high recovery can be prepared directly. The developed method offers a potential application for large-scale production of ursodeoxycholic acid.

Keywords: Ursodeoxycholic acid; Silylation; Separation

\section{Background}

Ursodeoxycholic acid ( $3 \alpha, 7 \beta$-2-hydroxy-5 $\beta$-cholanic acid, UDCA) is an important clinical drug used in the treatment of liver disease, such as gallstones [1], alcoholic fatty liver [2], nonalcoholic fatty liver [3], viral hepatitis [4], primary biliary cirrhosis [5], primary sclerosing cholangitis [6], and cholestatic [7].

UDCA was originally separated from the black bear [8]. In our previous work, UDCA was prepared by electroreduction of 7-ketolithocholic acid (3 $\alpha$-hydroxy-7oxo-5 $\beta$-cholanic acid, 7K-LCA) [9]. UDCA and its epimer chenodeoxycholic acid $(3 \alpha, 7 \alpha-2$-hydroxy-5 $\beta$ cholanic acid, CDCA) were both reduction products of $7 \mathrm{~K}-\mathrm{LCA}$; thus, the product of this electrochemistry conversion was a mixture of 7K-LCA, UDCA, and CDCA, which are difficult to separate. This problem limits its application in the production of UDCA. The structures of UDCA, 7K-LCA, and CDCA are shown in Figure 1.
Researchers have focused on the separation and purification of UDCA. Guillemette et al. [10] described the purification of UDCA by reacting an aqueous alkali metal salt solution of UDCA in the presence of chloroform with an acid to recover crystalline UDCA. Bonaldi et al. [11] prepared high-purity UDCA, starting from cholic acid by forming the tris-trimethylsilyl derivative acid thereof, reducing the acid by the Wolff-Kishner method into UDCA, and the total impurities were less than $1.3 \%$. Xu et al. [12] separated UDCA from its isomeric mixture using a core-shell molecular imprinting polymer, and the separation factor of the molecular imprinting polymer with acrylamide for UDCA was 2.20. Tian et al. [9] produced UDCA by catalytic transfer hydrogenation of 7K-LCA with Raney nickel, then UDCA was purified by column chromatography and recrystallized. Ninety-seven percent UDCA was obtained via this last method.

\footnotetext{
* Correspondence: caoxj@ecust.edu.cn

State Key Laboratory of Bioreactor Engineering, Department of

Bioengineering, East China University of Science \& Technology, 130 Meilong Rd., Shanghai 200237, China
}

\section{Springer}

(C) 2014 Ma and Cao; licensee Springer. This is an Open Access article distributed under the terms of the Creative Commons Attribution License (http://creativecommons.org/licenses/by/2.0), which permits unrestricted use, distribution, and reproduction in any medium, provided the original work is properly cited. 

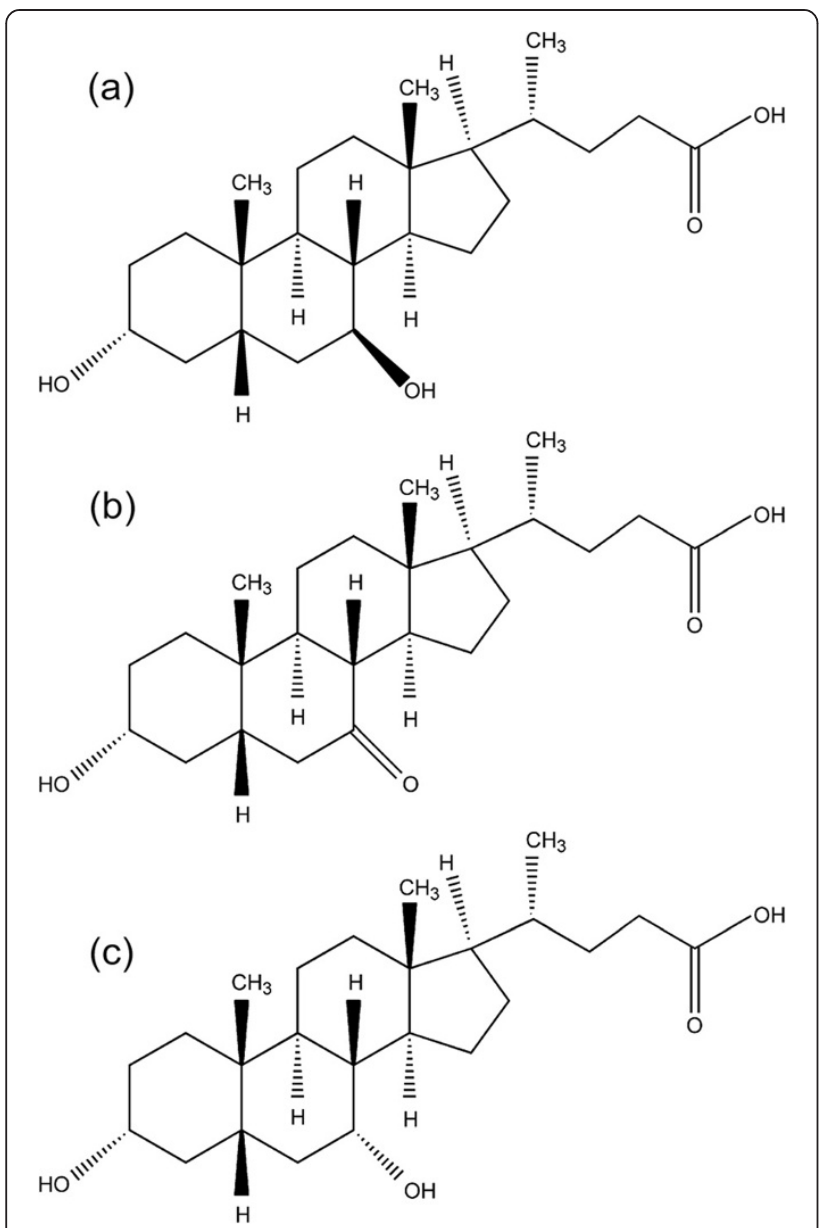

Figure 1 The structure of UDCA, 7K-LCA, and CDCA. (a) UDCA, (b) $7 \mathrm{~K}-\mathrm{LCA}$, and (c) CDCA.

Silylation is a powerful tool to improve the production process and the quality of the product in modern pharmaceutical and organic synthesis, and has been applied in increasing the volatility [13], changing the solubility in organic solvents [14], and the protection of sensitive functional groups such as hydroxyl and carboxyl moieties [15]. Silylation of alcohols and phenols with hexamethyldisilazane (HMDS) has been achieved using various types of catalysts [16-21]. The reaction conditions were nearly neutral, and the corresponding silyl ethers yields were high. Mormann et al. [22] reported the silylation of cellulose by HMDS in liquid ammonia and the reaction gave high degrees of silylation.

In this work, UDCA was isolated from the electroreduction product with analogues by silylation crystallization and UDCA. The process afforded UDCA with high purity and high recovery via a direct method.

\section{Methods}

\section{General methods}

The standard samples of UDCA, CDCA, and silylating reagents were purchased from Aladdin Chemistry Co. Ltd (Shanghai, China). 7K-LCA was prepared according to our previous work [9]. Acetonitrile and methanol were of highperformance liquid chromatography (HPLC) grade and purchased from Shanghai Xingke Biochemistry Co. Ltd (Shanghai, China). All other reagents were of analytical grade. HPLC (LC-20A, Shimadzu Corporation, Kyoto, Japan) with a UV detector (SPD-20A) using a C18 column (Welchrom-C18, $4.6 \times 150 \mathrm{~mm}, 5 \mu \mathrm{m}$, Welch Materials Inc. Shanghai, China) was used for quantification of the reaction products. Electron impact ionization time-of-flight mass spectrometry (EI-TOF-MS) (Micromass GCTTM, Micromass UK Ltd, Lancas, UK) and Fourier transform infrared spectroscopy (FTIR) (Magna-IR 550, Thermo Nicolet Ltd, Wisconsin, USA) were used for the characterization of the product and provided by the Analysis and Test Center, East China University of Science and Technology.

\section{Analytical methods}

(1) HPLC was used to analyze the product. The mobile phase was a mixture of phosphate acid buffer $(\mathrm{pH} 3.0)$ and acetonitrile $(50: 50, v / v)$ at a flow rate of $1.0 \mathrm{ml} / \mathrm{min}$ at $25^{\circ} \mathrm{C}$. Detection was performed using a UV detector at $208 \mathrm{~nm}$. UDCA was quantified by an external standard.

(2) EI-TOF-MS was used to identify the molecular weight of the derivatives.

(3) FTIR spectra with KBr pellets were used to analyze the structure of the product and the standard UDCA.

\section{Preparation of UDCA}

The synthesis procedure followed Yuan's method [23]. UDCA was synthesized in a divided electrolytic cell by direct electroreduction of 7K-LCA. A titanium ruthenium mesh electrode was used as the anode, and a high-purity lead plate was used as the cathode. Under the optimized process conditions, the content of UDCA was $47 \%$.

\section{Silylation crystallization}

Silylation crystallization experiments were carried out as below. One gram of the electroreduction product $(47 \%(w / w)$ of UDCA) was added into a $100-\mathrm{ml}$ conical

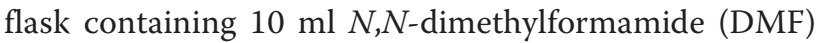
at $30^{\circ} \mathrm{C}$, and following the dissolution of the material under magnetic stirring at $150 \mathrm{rpm}, 1 \mathrm{ml}$ of HMDS was added into the solution. The conical flask was sealed with thread seal tape. The reaction was carried out for 


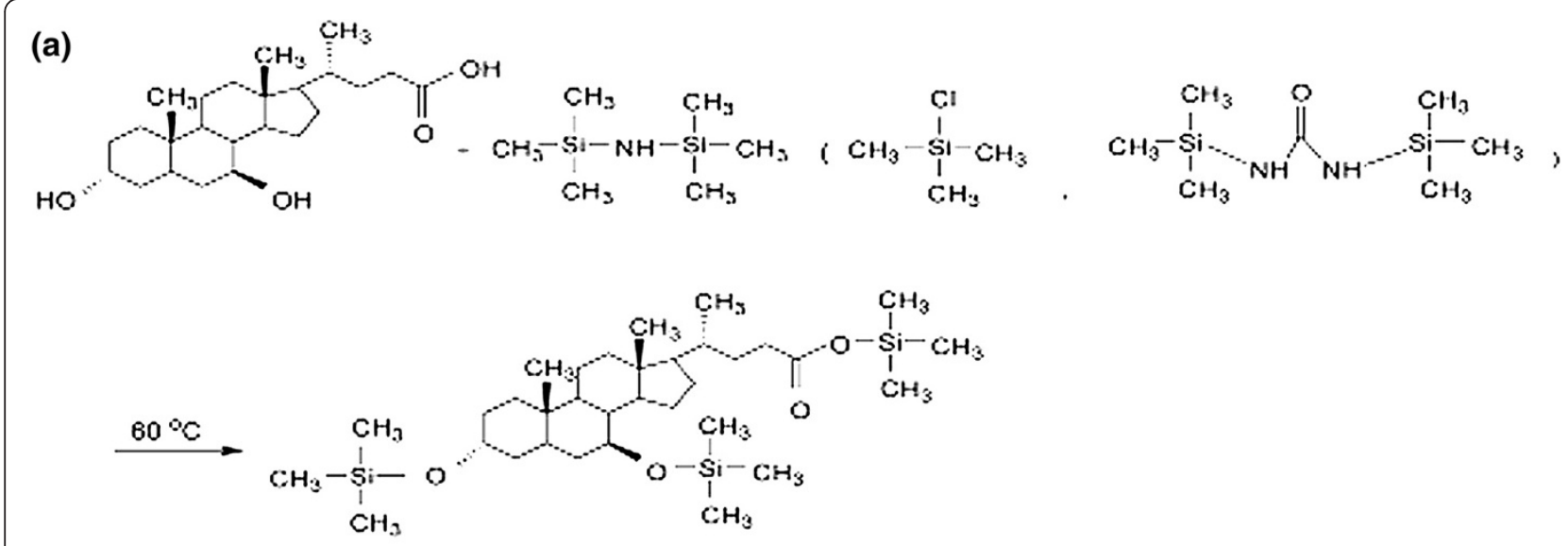

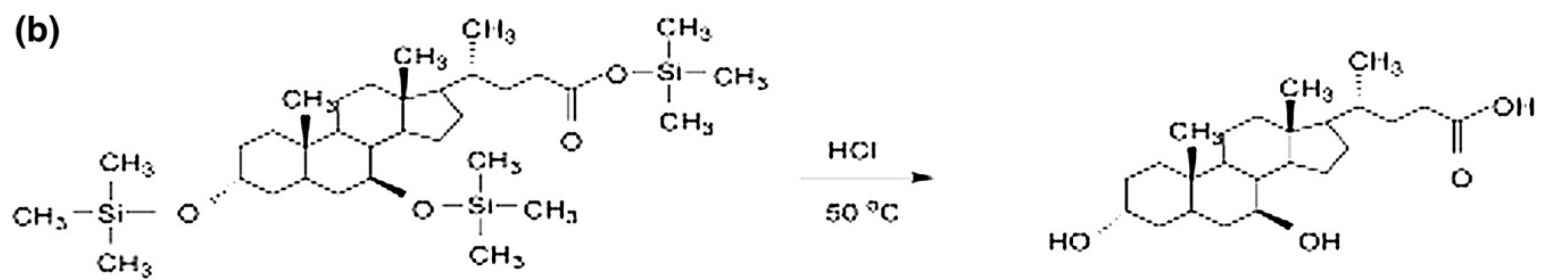

Scheme 1 The reaction formula of silylation and hydrolysis. (a) The silylation reaction formula. (b) The hydrolysis reaction formula. The different silylation derivatives, effects of silylation reagent types, temperature, and material ratio were measured.

$2 \mathrm{~h}$ at $30^{\circ} \mathrm{C}$ at a speed of $150 \mathrm{rpm}$. After the reaction was complete, the flask was moved to glacial water and maintained at $0^{\circ} \mathrm{C}$ for $24 \mathrm{~h}$. The crystalline material was collected by filtration and washed with the same silylating reagent and dried in a vacuum oven.

The silylation derivative of UDCA was then added to a $5 \%$ solution of hydrochloric acid, and the suspension was warmed to $50^{\circ} \mathrm{C}$ for $0.5 \mathrm{~h}$. After being cooled, the precipitate was collected by filtration, then washed with deionized water and dried in a vacuum oven. The recovery and purity of the product were measured. The reaction formula is shown in Scheme 1.

\section{Results and discussion}

\section{Selection of silylating reagents}

There are many kinds of silylation reagents. In this study, hexamethyldisilazane (HMDS), trimethylchlorosilane (TMCS), and 1,3-bis (trimethylsilyl) urea (BSU) were chosen as the silylating reagents.

The effect of different silylating reagents on UDCA recovery and purity is presented in Figure 2. These results indicate that the silylating reagent has an important effect on the recovery and purity of UDCA. In this study, when HMDS was used as the silylating reagent, maximal recovery and purity of UDCA were achieved with values of $87.7 \%$ and $90.4 \%$, respectively.
Since the boiling point of TMCS is $57.7^{\circ} \mathrm{C}$, the reaction took place intensively after TMCS was added to the system under the experimental temperature $\left(30^{\circ} \mathrm{C}\right)$, and TMCS evaporated. Consequently, the contact between reactants was reduced, and this made the final product yield

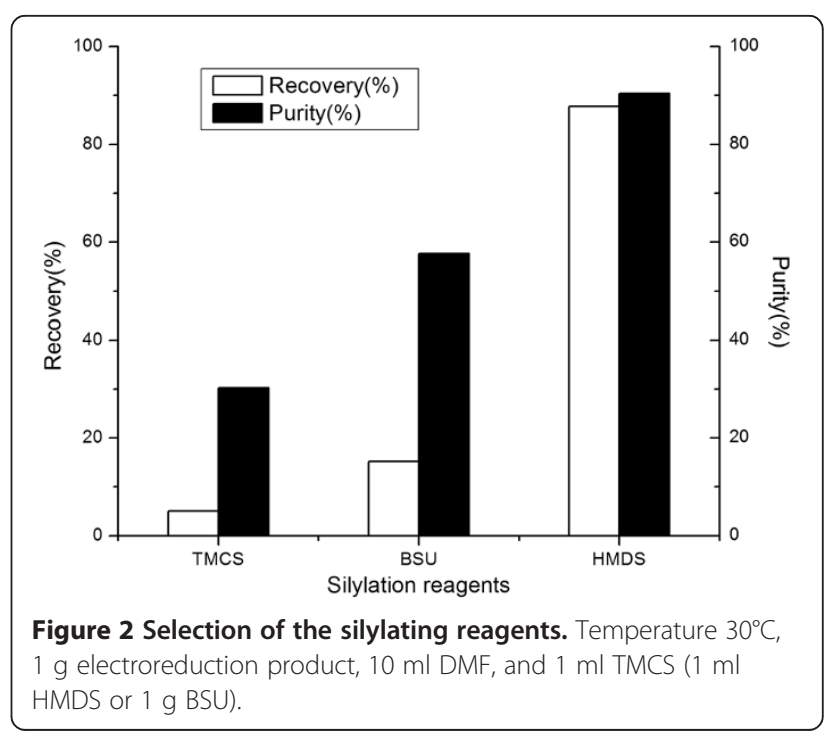


lower. BSU is a silylation reagent that can increase the solubility of the derivative of UDCA in DMF, so it is difficult to form a precipitant. HMDS, the commercially available reagent for trimethylsilylation of reactive hydrogen, is stable and yields ammonia as the only by-product, which is simple to remove from the reaction medium. Therefore, HMDS was chosen for the following study.

\section{Difference between the silylation derivatives}

Since a silylation reagent can replace the hydroxyl groups in UDCA, CDCA, and 7K-LCA, the difference between their corresponding silylation derivatives was the key to the subsequent success of the separation step. As such, silylation was conducted using standard samples (UDCA, CDCA, 7K-LCA, and their mixtures at different proportions) as the silylation reaction substrates and HMDS as the silylation reagent.

The difference between the silylation derivatives of UDCA, CDCA, and 7K-LCA is presented in Table 1. The results showed that crystallization was only observed when UDCA was present in the sample. When CDCA and 7K-LCA individually or together were used, no crystallization was observed. The tristrimethylsilyl derivative of UDCA has very low solubility in organic solvents, whereas the derivatives of $7 \mathrm{~K}$-LCA and CDCA are highly soluble in the same solvents. This suggested that HMDS can be used to isolate UDCA from CDCA and 7K-LCA.

\section{Influence of temperature}

The silylation reaction is a strongly exothermic reaction. Thus, temperature could affect the reaction to some extent. Thus, silylation was conducted over the temperature range of $20^{\circ} \mathrm{C}$ to $70^{\circ} \mathrm{C}$.

Table 1 Difference between the silylation derivatives

\begin{tabular}{lcccc}
\hline Groups & UDCA $(\mathbf{g})$ & CDCA $(\mathbf{g})$ & 7K-LCA $(\mathbf{g})$ & Crystallization \\
\hline 1 & 1.0 & 0 & 0 & Yes \\
2 & 0 & 1.0 & 0 & No \\
3 & 0 & 0 & 1.0 & No \\
4 & 0.8 & 0.2 & 0 & Yes \\
5 & 0.6 & 0.4 & 0 & Yes \\
6 & 0.4 & 0.6 & 0 & Yes \\
7 & 0.2 & 0.8 & 0 & Yes \\
8 & 0.8 & 0 & 0.2 & Yes \\
9 & 0.6 & 0 & 0.4 & Yes \\
10 & 0.4 & 0 & 0.6 & Yes \\
11 & 0.2 & 0 & 0.8 & Yes \\
12 & 0 & 0.5 & 0.5 & No \\
\hline
\end{tabular}

Temperature $30^{\circ} \mathrm{C}, 1 \mathrm{~g}$ electroreduction product, $10 \mathrm{ml} \mathrm{DMF}$, and $1 \mathrm{~g} \mathrm{HMDS}$.

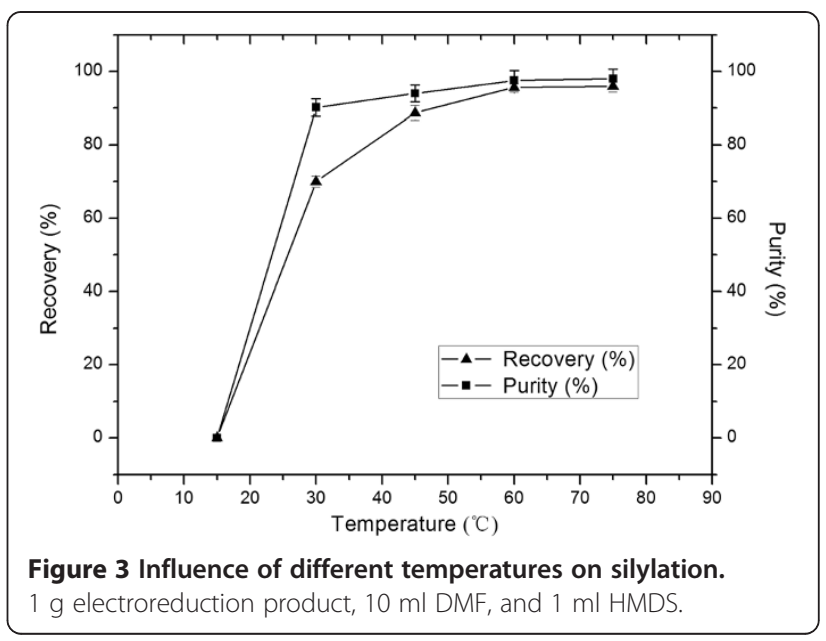

The effect of different temperatures on UDCA yield is shown in Figure 3. In the range of $20^{\circ} \mathrm{C}$ to $70^{\circ} \mathrm{C}$, the yield of UDCA increased as the reaction temperature increased. This indicated that the reaction was an endothermic reaction. When the temperature was $60^{\circ} \mathrm{C}$, the recovery and purity of UDCA were $95.6 \%$ and $97.5 \%$, respectively. The use of higher temperatures did not lead to further increases in yield. Consequently, $60^{\circ} \mathrm{C}$ was chosen for the following study. Under this temperature, the reaction was mild and only a small amount of ammonia was produced as a by-product.

\section{Influence of the material ratio}

The ratio of reactants needs to be controlled, so silylation was conducted at different material ratios of electroreduction product, DMF, and HMDS. Table 2 presents the effect of different material ratios on the yield and purity of UDCA.

Table 2 Influence of different material ratios

\begin{tabular}{lccccc}
\hline Groups & $\begin{array}{l}\text { DMF } \\
(\mathbf{m l})\end{array}$ & $\begin{array}{l}\text { Electroreduction } \\
\text { product (g) }\end{array}$ & $\begin{array}{l}\text { HMDS } \\
(\mathbf{m l})\end{array}$ & $\begin{array}{l}\text { Recovery } \\
(\%)\end{array}$ & $\begin{array}{l}\text { Purity } \\
(\%)\end{array}$ \\
\hline 1 & 10.0 & 1.0 & 1.0 & 60.4 & 92.5 \\
2 & 10.0 & 1.0 & 2.0 & 99.8 & 99.5 \\
3 & 10.0 & 1.0 & 3.0 & 87.6 & 94.6 \\
4 & 10.0 & 2.0 & 1.0 & 40.3 & 90.1 \\
5 & 10.0 & 2.0 & 2.0 & 45.6 & 91.2 \\
6 & 10.0 & 2.0 & 3.0 & 50.8 & 92.8 \\
7 & 15.0 & 1.0 & 1.0 & 30.2 & 93.3 \\
8 & 20.0 & 1.0 & 1.0 & 26.4 & 90.6 \\
\hline Temperature $60^{\circ} \mathrm{C} ;$ silylation reagent, HMDS. & & &
\end{tabular}



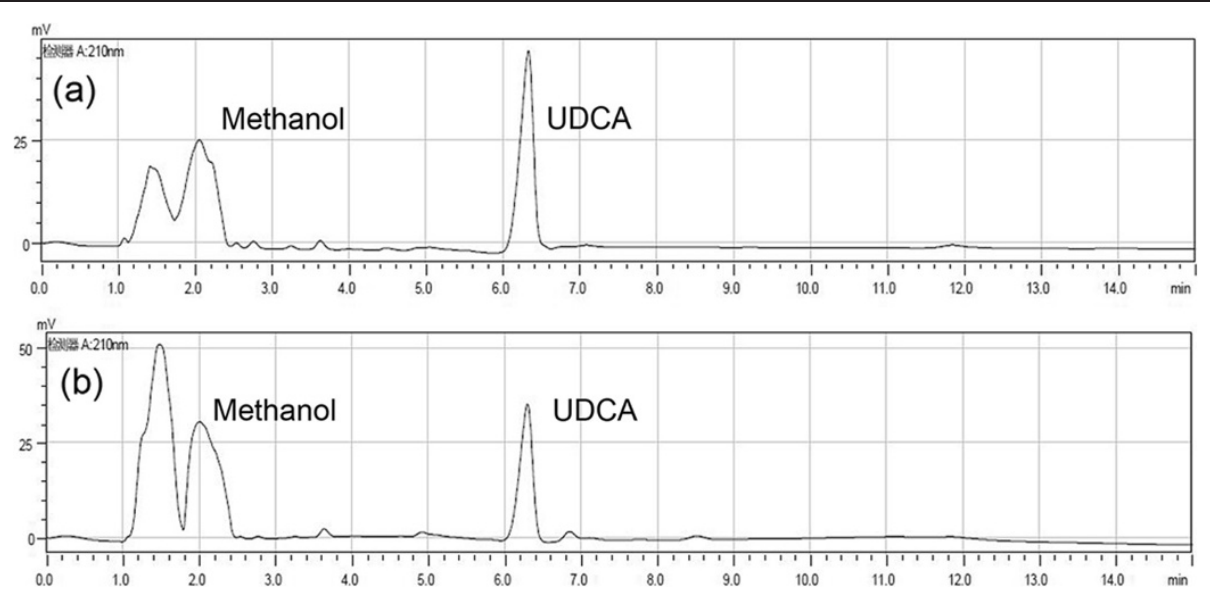

Figure 4 The HPLC spectrum of the product and standard spectrum of UDCA. Mobile phase was a mixture of acetonitrile and phosphate acid buffer ( $\mathrm{pH} 3.0$ ) with a volume ratio of $50: 50$ at a flow rate of $1.0 \mathrm{ml} / \mathrm{min}$ at $25^{\circ} \mathrm{C}$. (a) Standard UDCA and (b) product.

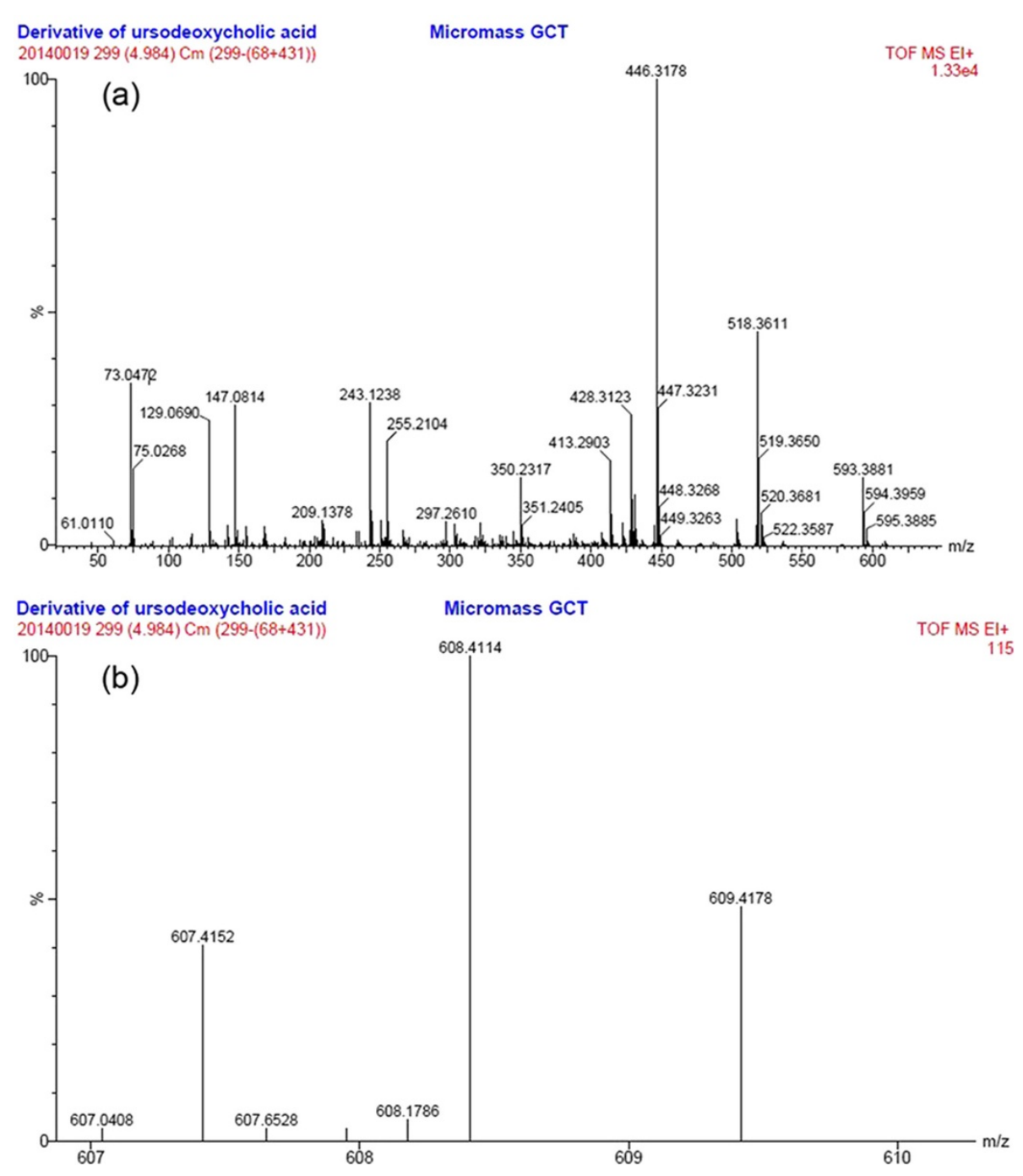

Figure 5 The EI-TOF-MS spectra of the derivative of UDCA. (a) The $\mathrm{m} / \mathrm{z}$ ranged from 0 to 600 . (b) The $\mathrm{m} / \mathrm{z}$ ranged from 605 to 610 . 
Table 3 Formula evaluated by multiple mass analysis

\begin{tabular}{|c|c|c|c|c|c|c|}
\hline Minimum & 4.00 & & & & -1.5 & \\
\hline Maximum & 100.00 & & 5.0 & 5.0 & 50.0 & \\
\hline Mass & Relative abundance & Calculated mass & $\mathrm{mDa}$ & PPM & Double bond equivalents & Formula \\
\hline 73.0472 & 34.67 & 73.0474 & -0.2 & -2.1 & 0.5 & $\mathrm{C}_{3} \mathrm{H}_{9} \mathrm{Si}$ \\
\hline 147.0814 & 30.08 & 147.0841 & -2.7 & -18.6 & 0.5 & $\mathrm{C}_{6} \mathrm{H}_{15} \mathrm{O}_{2} \mathrm{Si}$ \\
\hline 243.1238 & 4.43 & 243.1205 & 3.3 & 13.5 & 7.5 & $\mathrm{C}_{15} \mathrm{H}_{19} \mathrm{OSi}$ \\
\hline 350.2317 & 14.64 & 350.2277 & 4.0 & 11.4 & 5.0 & $\mathrm{C}_{20} \mathrm{H}_{34} \mathrm{O}_{3} \mathrm{Si}$ \\
\hline 413.2903 & 18.26 & 413.2876 & 2.7 & 6.6 & 7.5 & $\mathrm{C}_{26} \mathrm{H}_{41} \mathrm{O}_{2} \mathrm{Si}$ \\
\hline 428.3123 & 28.07 & 428.3111 & 1.2 & 2.9 & 7.0 & $\mathrm{C}_{27} \mathrm{H}_{44} \mathrm{O}_{2} \mathrm{Si}$ \\
\hline 446.3178 & 100.00 & 446.3216 & -3.8 & -8.6 & 6.0 & $\mathrm{C}_{27} \mathrm{H}_{46} \mathrm{O}_{3} \mathrm{Si}$ \\
\hline 518.3611 & 45.94 & 518.3612 & -0.1 & -0.1 & 6.0 & $\mathrm{C}_{30} \mathrm{H}_{53} \mathrm{O}_{3} \mathrm{Si}_{2}$ \\
\hline 608.4114 & 100.00 & 608.4112 & 0.2 & 0.3 & 5.0 & $\mathrm{C}_{33} \mathrm{H}_{64} \mathrm{O}_{4} \mathrm{Si}_{3}$ \\
\hline
\end{tabular}

Multiple mass analysis, 37 mass(es) processed. Tolerance $=5.0 \mathrm{mDa}$ /double bond equivalents: $\min =-1.5$, $\max =50.0$. Isotope cluster parameters: separation $=1.0$, abundance $=1.0 \%$.

When the material ratio of electroreduction product/ DMF/HMDS was 1:10:2 $(w / v / v)$, the recovery and purity of UDCA were $99.8 \%$ and $99.5 \%$, respectively. With $1 \mathrm{ml}$ HMDS present, the reaction did not complete; however, when $3 \mathrm{ml}$ of HMDS was used, the silylation derivative of UDCA did not readily form a crystal because of the increase of HMDS in the solution. A comparison of group 2 with groups 4, 5, and 6 showed that excessive crude UDCA made the reaction system too viscous to react.

\section{Characterization of the product}

After being hydrolyzed and dried, the product was determined by HPLC, EI-TOF-MS, and FTIR.

\section{Characterization by HPLC}

As presented in Figure 4a, the retention time of the product was $6.3 \mathrm{~min}$ and consistent with the standard HPLC spectrum of UDCA (Figure 4b). In the range of 0 to $20 \mathrm{mg} / \mathrm{ml}$, the peak area of the standard UDCA sample and its concentration gave a linear correlation, with the standard curve of UDCA being $A=226,034.6 C+18,928.2$ ( $A$ is the for peak area, $C$ stands for concentration, $\left.R^{2}=0.9997\right)$. The sample was run under identical conditions as the standard UDCA material, and the recovery and purity were calculated according to an external standard method.

\section{Characterization by EI-TOF-MS}

The EI-TOF-MS spectrum of the tris-trimethylsilyl derivative of UDCA is shown in Figure 5 and Table 3.
The spectrum showed its characteristic fragmentation ions at $m / z 608$ (100), 593 (14), 518 (45), 446 (100), 428 (28), 413 (18), 350 (14), 243 (30), 147 (30), and 73 (34). The evaluation formulas corresponding to these fragments are listed in Table 3. As observed, the ion at $\mathrm{m} / \mathrm{z} 608$ corresponds to the tristrimethylsilyl derivative of UDCA $\left(\mathrm{C}_{33} \mathrm{H}_{64} \mathrm{O}_{4} \mathrm{Si}_{3}\right)$. This result proved that the reaction proceeded and indicated that the active hydrogen atoms of the three hydroxyl groups on UDCA were substituted by silylation.

\section{Characterization by FTIR}

The FTIR spectrum is shown in Figure 6. It indicated that -Si-O- $\left(839.36 \mathrm{~cm}^{-1}, \quad 1,080.8 \mathrm{~cm}^{-1}\right), \quad-\mathrm{Si}-\mathrm{C}-$ $\left(1,250 \mathrm{~cm}^{-1}\right),-\mathrm{C}-\mathrm{H}\left(2,867.6 \mathrm{~cm}^{-1}, 2,943.7 \mathrm{~cm}^{-1}\right)$, and $\mathrm{CH}_{3}\left(1,380.0 \mathrm{~cm}^{-1}\right)$ existed in the structure of the derivative of UDCA. Thus, the silylation reaction was confirmed, and the FTIR spectrum of the product is consistent with the standard FTIR spectrum of UDCA.

\section{Conclusions}

Ursodeoxycholic acid was purified by silylation crystallization in this study. By optimizing process conditions, recovery and purity of ursodeoxycholic acid was up to $99.8 \%$ and $99.5 \%$, respectively. HPLC, EI-TOF-MS, and FTIR analysis showed that silylation is a highly efficient purification method of ursodeoxycholic acid. Compared with previous methods, the UDCA preparation methods presented herein (i) gave higher purity and recovery, (ii) avoided cumbersome procedures, (iii) was more cost efficient, and 

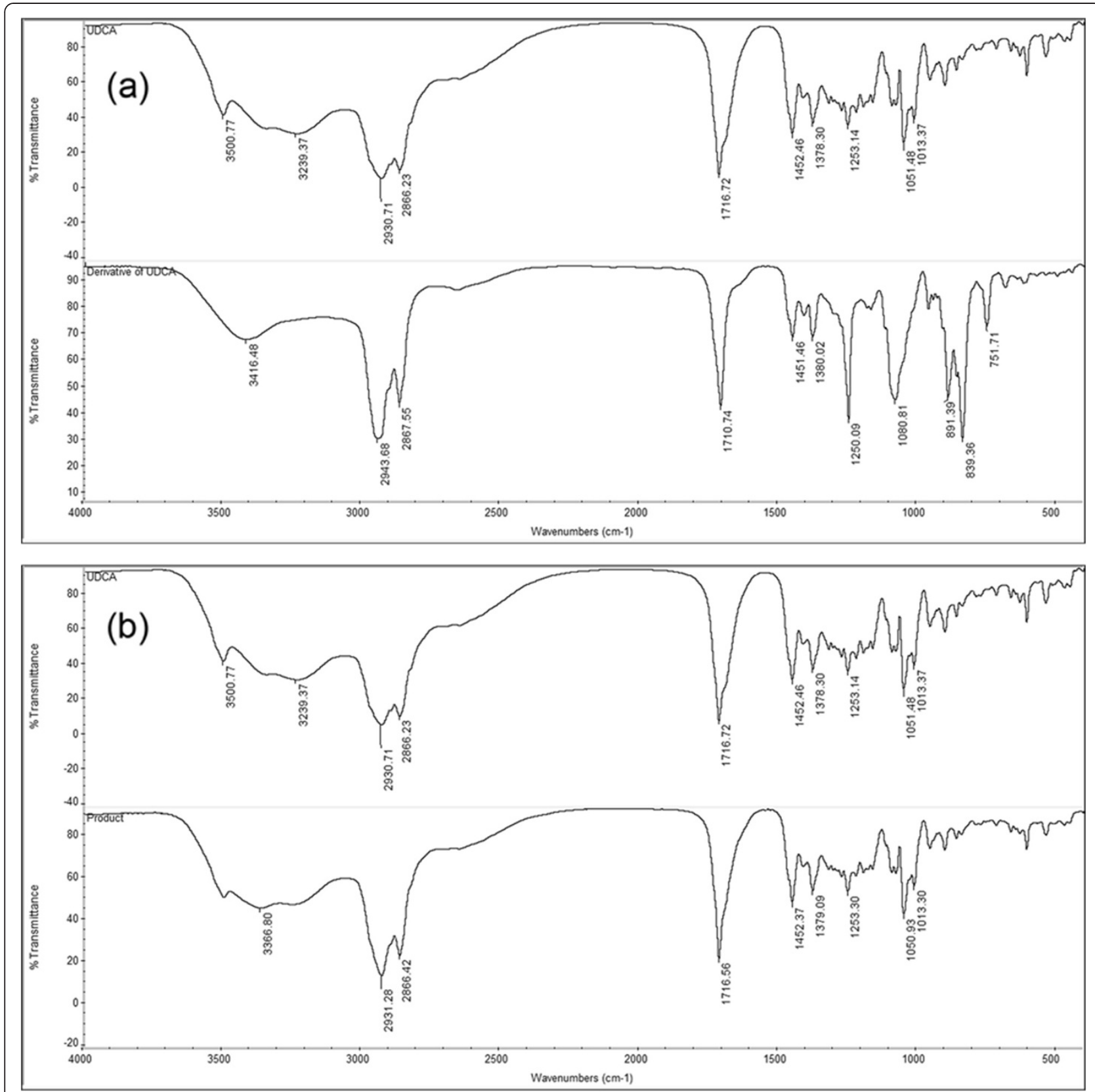

Figure 6 The FTIR spectrum of UDCA, derivative of UDCA, and product (KBr pellet). (a) UDCA and derivative. (b) UDCA and product.

(iv) did not require harsh reaction conditions. The silylation crystallization approach was easy to operate, economic, and timesaving, and the by-product (i.e., ammonia) was simple to remove from the reaction medium.

\section{Abbreviations}

BSU: 1,3-bis(trimethylsilyl)urea; CDCA: chenodeoxycholic acid; DMF: N,Ndimethylformamide; El-TOF-MS: electron impact ionization time-of-flight mass spectrometry; FTIR: Fourier transform infrared spectroscopy;

HMDS: hexamethyldisilazane; HPLC: high-performance liquid chromatography; TMCS: trimethylchlorosilane; UDCA: ursodeoxycholic acid; 7K-LCA: 7-ketolithocholic acid.

Competing interests

The authors declare that they have no competing interests.

\section{Authors' contributions}

$X L M$ designed the study; collected, processed, and analyzed the data; and wrote the article. XJC contributed to study design and article corrections. Both authors have read and approved the final manuscript. 
Received: 5 May 2014 Accepted: 30 May 2014

Published: 23 July 2014

\section{References}

1. Maton P, Murphy G, Dowling R (1977) Ursodeoxycholic acid treatment of gallstones: dose-response study and possible mechanism of action. Lancet 310(8052):1297-1301

2. Lukivskaya OY, Maskevich AA, Buko VU (2001) Effect of ursodeoxycholic acid on prostaglandin metabolism and microsomal membranes in alcoholic fatty liver. Alcohol 25(2):99-105

3. Matteoni CA, Younossi ZM, Gramlich T, Boparai N, Liu YC, McCullough AJ (1999) Nonalcoholic fatty liver disease: a spectrum of clinical and pathological severity. Gastroenterology 116(6):1413-1419

4. De Lalla F (1999) Effect of ursodeoxycholic acid administration in patients with acute viral hepatitis: a pilot study. Aliment Pharmacol Therapeut 13(9):1187-1193

5. Poupon R, Poupon R, Calmus Y, Chrétien Y, Ballet F, Darnis F (1987) Is ursodeoxycholic acid an effective treatment for primary biliary cirrhosis? Lancet 329(8537):834-836

6. Pardi DS, Loftus EV Jr, Kremers WK, Keach J, Lindor KD (2003) Ursodeoxycholic acid as a chemopreventive agent in patients with ulcerative colitis and primary sclerosing cholangitis. Gastroenterology 124(4):889-893

7. Paumgartner $\mathrm{G}$, Beuers $U$ (2002) Ursodeoxycholic acid in cholestatic liver disease: mechanisms of action and therapeutic use revisited. Hepatology 36(3):525-531

8. Shoda M (1927) Über die Ursodesoxycholsäure aus Bärengallen und ihre physiologische Wirkung. J Biochem 7(3):505-517

9. Tian H, Zhao HB, Cao XJ (2012) Catalytic transfer hydrogenation of 7-ketolithocholic acid to ursodeoxycholic acid with Raney nickel. J Ind Eng Chem 19:606-613

10. Guillemette A, Francois A (1981) Novel purification process. United States Patent and Trademark Office, US Patent 4,282,161. 4 Aug 1981

11. Bonaldi A, Molinari E (1982) Process for preparing high purity ursodeoxycholic acid. United States Patent and Trademark Office, US Patent 4,316,848. 23 Feb 1982

12. Xu ZY, Wan JF, Liang S, Cao XJ (2008) Separation of ursodeoxycholic acid from its isomeric mixture using core-shell molecular imprinting polymer. Biochem Eng J 41(3):280-287

13. Halket JM, Zaikin VG (2003) Derivatization in mass spectrometry-1: silylation. Eur J Mass Spectrom 9(1):1-21

14. Goussé C, Chanzy H, Excoffier G, Soubeyrand L, Fleury E (2002) Stable suspensions of partially silylated cellulose whiskers dispersed in organic solvents. Polymer 43(9):2645-2651

15. Yamamoto K, Takemae M (1989) The utility of t-butyldimethylsilane as an effective silylation reagent for the protection of functional groups. B Chem Soc Jpn 62(6):2111-2113

16. Karimi B, Golshani B (2000) Mild and highly efficient method for the silylation of alcohols using hexamethyldisilazane catalyzed by iodine under nearly neutral reaction conditions. J Org Chem 65(21):7228-7230

17. Khazaei A, Zolfigol MA, Rostami A, Choghamarani AG (2007) Trichloroisocyanuric acid (TCCA) as a mild and efficient catalyst for the trimethylsilylation of alcohols and phenols with hexamethyldisilazane (HMDS) under heterogonous conditions. Catal Commun 8(3):543-547

18. Kadam ST, Kim SS (2009) Mild and efficient silylation of alcohols and phenols with HMDS using $\mathrm{Bi}(\mathrm{OTf})_{3}$ under solvent-free condition. J Organomet Chem 694(16):2562-2566

19. Shirini F, Mamaghani M, Atghia SV (2012) A mild and efficient method for the chemoselective trimethylsilylation of alcohols and phenols and deprotection of silyl ethers using sulfonic acid-functionalized ordered nanoporous $\mathrm{Na}^{+}$-montmorillonite. Appl Clay Sci 58:67-72

20. Zareyee D, Ghandali MS, Khalilzadeh MA (2011) Sulfonated ordered nanoporous carbon (CMK-5-SO3H) as an efficient and highly recyclable catalyst for the silylation of alcohols and phenols with hexamethyldisilazane (HMDS). Catal lett 141(10):1521-1525

21. Lee SH, Kadam ST (2011) Cross-linked poly (4-vinylpyridine/styrene) copolymer-supported bismuth(III) triflate: an efficient heterogeneous catalyst for silylation of alcohols and phenols with HMDS. Appl Organomet Chem 25(8):608-615
22. Mormann W, Wagner T (2000) Silylation of cellulose with hexamethyldisilazane in liquid ammonia. Carbohyd Polym 43(3):257-262

23. Yuan XX, Ma XL, Cao XJ (2014) Preparation of ursodeoxycholic acid by direct electro-reduction of 7-ketolithocholic acid. Korean J Chem Eng 1-5. doi:10.1007/s11814-013-0245-y

doi:10.1186/s40643-014-0005-9

Cite this article as: Ma and Cao: Separation of ursodeoxycholic acid by silylation crystallization. Bioresources and Bioprocessing 2014 1:5.

\section{Submit your manuscript to a SpringerOpen ${ }^{\circ}$ journal and benefit from:}

- Convenient online submission

- Rigorous peer review

- Immediate publication on acceptance

- Open access: articles freely available online

- High visibility within the field

- Retaining the copyright to your article

Submit your next manuscript at $>$ springeropen.com 